

\title{
APRENDIZAJE COLABORATIVO MEDIATIZADO COMO ESTRATEGIA PARA EL DESARROLLO DE COMPETENCIAS: UNA EXPERIENCIA CON RESIDENTES DEL PROFESORADO DE MATEMÁTICA
}

Resumen: La implementación de tecnologías como recursos didácticos utilizadas en la educación implica el desarrollo de diferentes habilidades entre las que podemos destacar: conocer nuevos modelos de comunicación, saber diferentes formas de manipular la información, poder emplear variados formatos de transmisión de contenidos y trabajar interactuando en forma colaborativa.

Esta necesidad demanda que los docentes se actualicen, pero, a su vez, es imprescindible la incorporación de este tipo de actividades en las carreras de formación docente. Intentando aportar una experiencia en esta línea, el presente trabajo presenta una novedosa variante aplicada en la cátedra de Residencia del Profesorado de Matemática de la Facultad de Ciencias Exactas, Ingeniería y Agrimensura de la Universidad Nacional de Rosario. Se trata de la realización de una tarea compartida que involucra un espacio de gestión de conocimiento, socialización y uso de tecnologías empleando el espacio virtual y las herramientas de la web 2.0.

Palabras clave: Formación docente; aprendizaje colaborativo; Matemática; Google docs

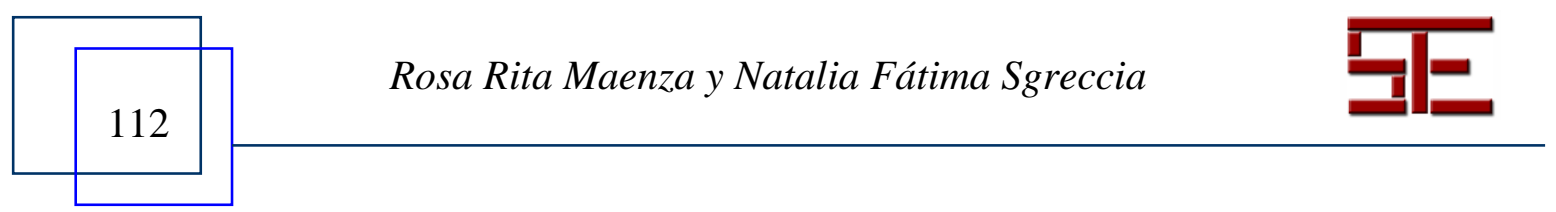




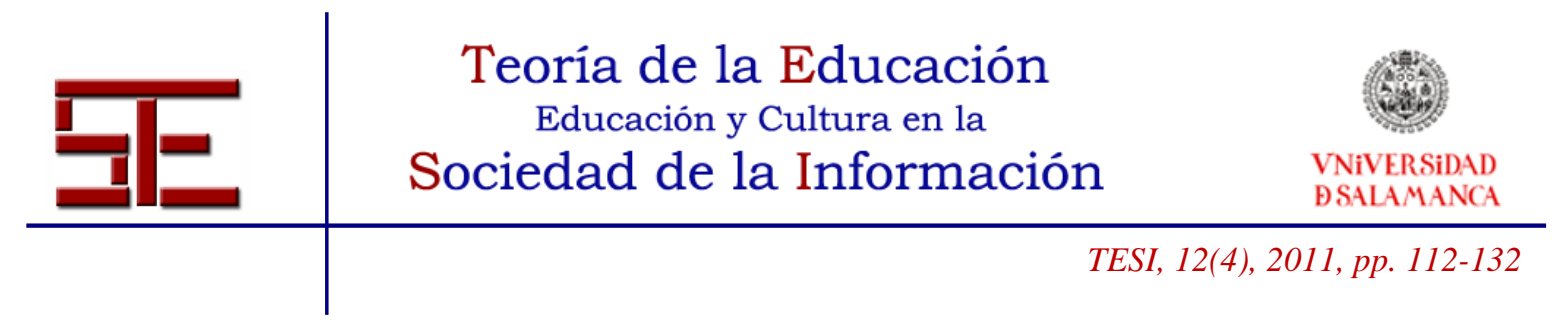

\title{
MEDIATED COLLABORATIVE LEARNING AS A STRATEGY FOR THE DEVELOPMENT OF SKILLS: AN EXPERIENCE WITH RESIDENTS OF TEACHERS OF MATHEMATICS
}

\begin{abstract}
The implementation of technologies as teaching resources used in education involves the development of different skills among which are: meeting new models of communication, knowing different ways to manipulate information, to use various content delivery formats and work interacting collaboratively. This need to demand the teaching to updated, but in turn, is essential to incorporate these activities in teacher training courses. Trying to provide an experience in this line, this paper presents a novel variant applied of residence of Teachers of Mathematics, Faculty of Sciences, Engineering and Surveying of the Universidad Nacional de Rosario. This is the realization of a shared task involving an area of knowledge management, socialization, and use of technology and virtual space using the tools of Web 2.0.
\end{abstract}

Keywords: Training teachers; collaborative learning; Mathematics; Google docs.

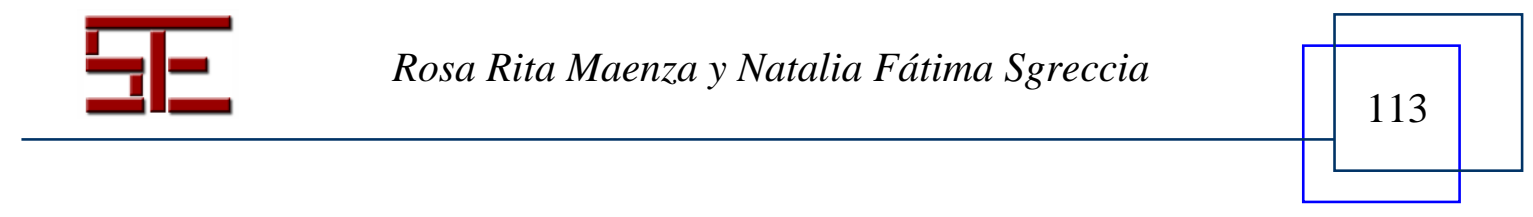




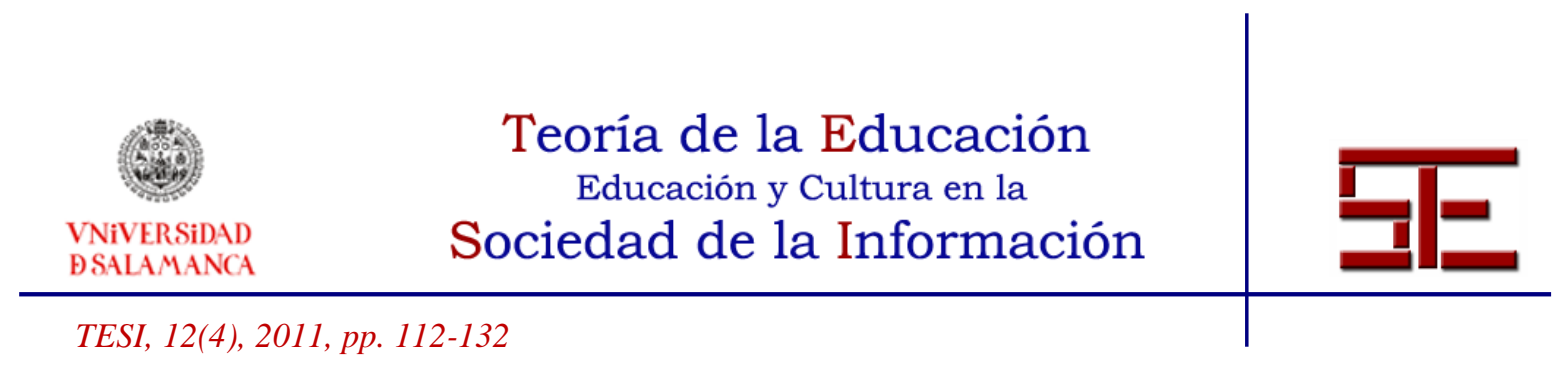

\begin{abstract}
APRENDIZAJE COLABORATIVO MEDIATIZADO COMO ESTRATEGIA PARA EL DESARROLLO DE COMPETENCIAS: UNA EXPERIENCIA CON RESIDENTES DEL PROFESORADO DE MATEMÁTICA
\end{abstract}

Fecha de recepción: 31/10/2011; fecha de aceptación: 20/11/2011; fecha de publicación: 20/12/2011

\author{
Rosa Rita Maenza \\ nataliasgreccia@gmail.com \\ Universidad Nacional Rosario \\ Natalia Fátima Sgreccia \\ nataliasgreccia@gmail.com \\ Universidad Nacional Rosario
}

\title{
1.- INTRODUCCIÓN
}

En los últimos años, las aplicaciones y los servicios que forman parte de la denominada web 2.0 han permitido que el uso de la computadora y, en particular, el empleo de Internet fuera posible no solo para profesionales informáticos. Este fenómeno se complementa con la característica de interacción cultural constante, donde el desarrollo y la mejora de estos entornos digitales se producen según el uso dado a los mismos. Es decir, son los propios usuarios quienes mientras los utilizan establecen las formas de consumo y manipulación, combinando datos de variadas fuentes y creando efectos de red por medio de una arquitectura de participación (O’Reilly, 2005).

Coincidiendo con este pensamiento Pierre Lévy (2007) afirma que las tecnologías no son algo autónomo que aparece y desaparece al margen del entorno en que se producen; señala además "las tecnologías son el producto de una sociedad y de una cultura" (p:7), y agrega" una técnica se produce en una cultura, y una sociedad se encuentra condicionada por su técnica y no determinada" ( pp.9-10).

Ante esta realidad actual, donde los cambios en las formas de consumo se están llevando a cabo de manera sutil y gradual, nuevamente vuelven a ponerse en cuestión ideas antagónicas de tecnofóbicos y tecnofílicos.

Así, Carr, en su libro Superficiales, muestra una visión poco alentadora respecto a los posibles inconvenientes que acarreará para una sociedad futura el uso exacerbado de las Tecnologías de la Información y la Comunicación (Carr, 2011). Para el autor el

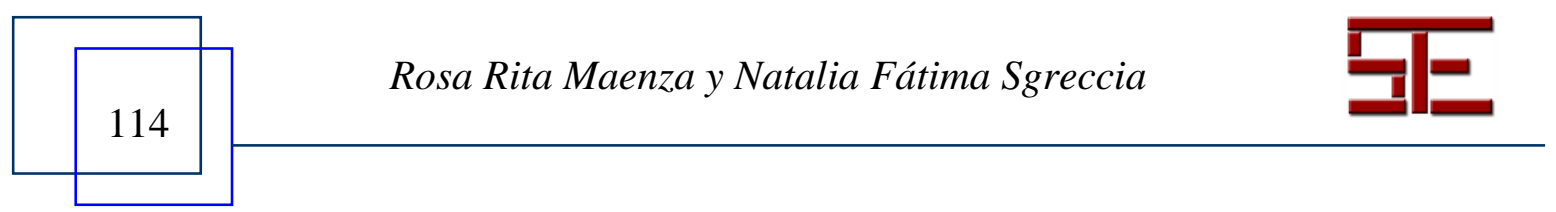




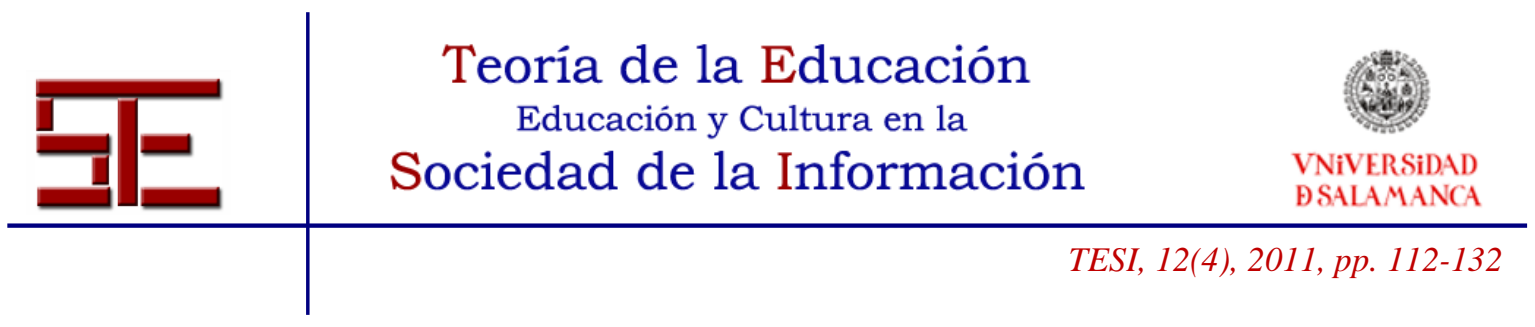

paradigma hipertextual y la multiplicidad de fuentes proporcionadas por Internet hacen que las lecturas sean cada vez menos profundas y acostumbran a la mente a perder la capacidad de analizar y razonar de forma introspectiva, profundizando en los contenidos. Carr señala que al navegar en el ciberespacio, saltando de un tema a otro, se pierde el foco y se favorece la distracción y dispersión provocando que la calidad de la mente disminuya de forma irreversible. Vista de esta forma, la web amenaza el conocimiento y será la responsable de un apocalipsis cultural e intelectual.

En otro extremo, adoptando una postura más tecnofílica, Copertari y Trottini (2011) afirman que la revolución de la web 2.0 creó un nuevo mundo: el de la sabiduría colectiva. Según las autoras, Internet es una herramienta perfecta para recopilar y compartir esa sabiduría; por lo que habrá que "aprender a gestionar la inteligencia colectiva" y llegar a una nueva definición del concepto de innovación.

En este marco, el espacio proporcionado en Internet puede ser considerado como una "biblioteca universal abierta" donde se promueve que el flujo y la organización de la información dependan del comportamiento de las personas que la utilizan, proporcionando facilidad de acceso, focalización de contenidos y herramientas simples de emplear (De la Torre, 2006). Con esta nueva forma de gestionar la información, puede decirse que la manera de tratamiento del conocimiento ha cambiado, pasando de categorías y jerarquías a redes y ecologías (Siemens, 2006).

Sin duda una transformación en la sociedad está aconteciendo, en especial, nuestros próximos alumnos serán asiduos consumidores de diversos soportes digitales, con una importante experiencia de aprendizaje basada primordialmente en lo audiovisual e informal. Acostumbrados a la instantaneidad y a lo efímero, buscarán en los espacios escolares ese tipo de forma natural de comunicarse.

Ante este nuevo fenómeno social que está sucediendo y en un intento de realizar ajustes educativos significativos, el informe OEI (2009) propone como metas para el año 2021 en Iberoamérica, la incorporación de las TIC al proceso de enseñanza y aprendizaje, justificando que la inclusión social se vincula, con el acceso al conocimiento, por la participación en redes y por el uso de tales tecnologías.

En Argentina, desde el año 2009, se están realizando acciones específicas desde el Ministerio de Educación de la Nación que involucran directamente este tipo de objetivos, siendo el Programa "Conectar Igualdad" (http://www.conectarigualdad.gob.ar/) el mega proyecto destinado a recuperar y

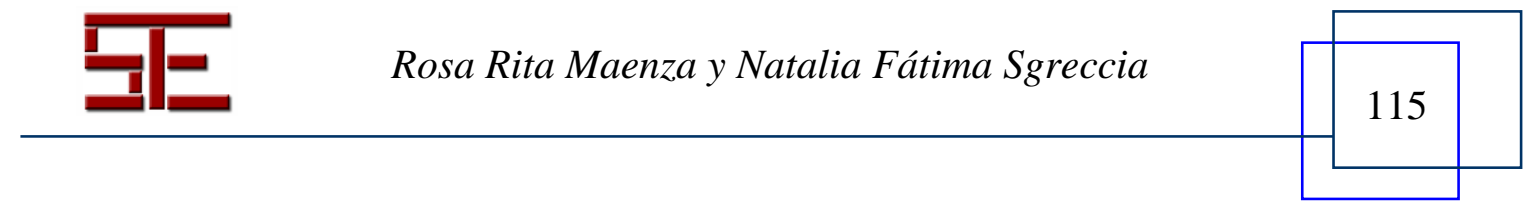




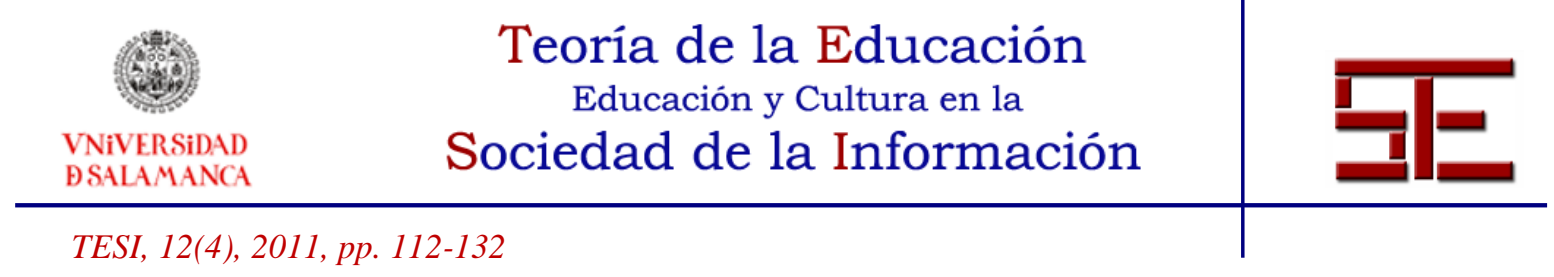

valorizar la escuela pública reduciendo las brechas digitales, educativas y sociales en todo el país mediante la entrega de netbooks y la capacitación en el uso de las mismas, dirigida a docentes y alumnos de nivel medio.

Continuando la misma línea de acción tendiente a incorporar el uso de las TIC en la educación, una transformación importante debe llevarse a cabo en las instituciones de nivel superior. Así, se considera importante y necesario impulsar en las universidades lo que se ha llamado "actitud 2.0", donde los principios de mejora continua: compartir, reutilizar, generar confianza y alfabetizar en tecnologías, posibilitan el aprovechamiento de la inteligencia colectiva (Arnal, 2007).

El objetivo principal en este posicionamiento es tender a la construcción de Comunidades Virtuales de Práctica (CVP), donde existe un grupo de personas que comparten una preocupación, problema o interés común acerca de un tema, y que profundizan su conocimiento y pericia en esa área a través de una interacción continuada (Wenger, 2001).

Las CPV incluyen cuatro dimensiones o elementos claves que las caracterizan: el dominio (temática de interés compartida); la comunidad (comprometida en llevar a cabo actividades y discusiones conjuntas, ayudándose entre los miembros); la práctica (se desarrolla un repertorio compartido de recursos) y el uso de las tecnologías dadas por Internet (Wenger, McDermott y Snyder, 2002).

En el ámbito educativo universitario de nuestra realidad profesional, podemos hablar de una CVP al pensar en un grupo de alumnos del Profesorado en Matemática que desarrollan significados compartidos por medio del uso de Google Docs. Es en ese contexto de análisis que el siguiente trabajo será desarrollado.

\section{2.- FORMACIÓN DEL PROFESORADO}

Recientemente en el IV Encuentro Internacional EducaRed 2011, realizado por la Fundación Telefónica en forma virtual y presencial para España y Latinoamérica, varias presentaciones y charlas expusieron sobre la problemática de la formación del profesorado.

En particular, la ponente Judi Harris presentó una nueva comprensión de la integración de las TIC basada en el currículum, destacando la necesidad de integrar las tecnologías

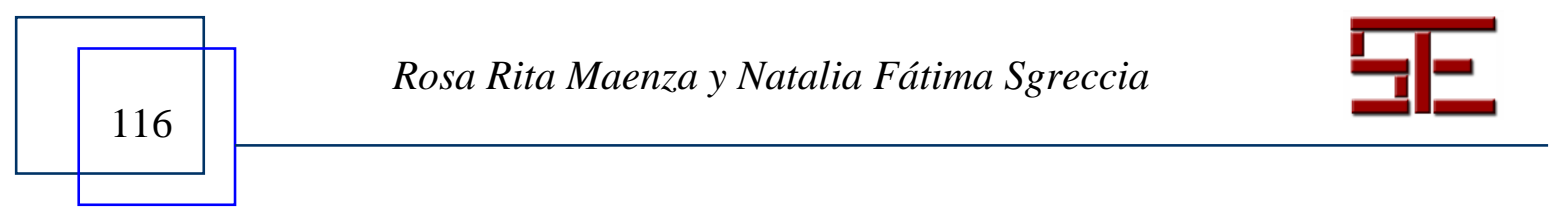




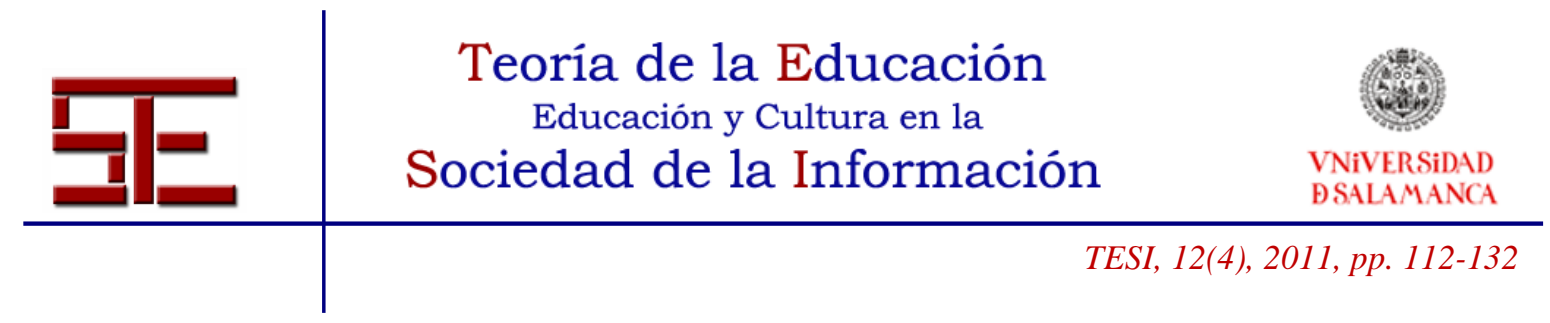

de forma eficaz. La docente señala la importancia de trabajar con los diferentes tipos de conocimiento: el curricular, el pedagógico y el tecnológico, y con sus respectivas intersecciones, llamando "TPACK" al sector conjuntista determinado por los tres tipos de conocimientos.

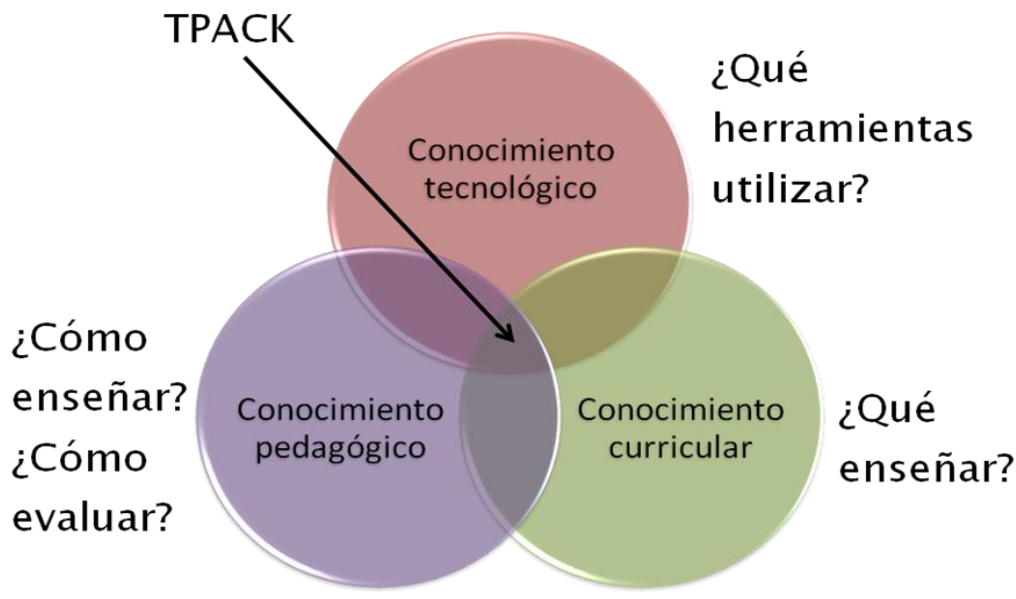

Figura 1 - Integración de las TIC basada en el currículum (Judi Harris).

Se entiende por conocimiento curricular el contenido determinado sobre qué deben saber los estudiantes, el conocimiento pedagógico implica cómo enseñarles con eficacia y el conocimiento tecnológico proporciona la idea de qué tecnologías emplear para el proceso de enseñanza-aprendizaje.

La intersección de contenido y pedagogía se vincula con las ideas de Lee Shulman (1986) y la necesidad de enseñar teniendo en cuenta un contenido concreto, así la especificidad disciplinar implica necesariamente el empleo de ciertas estrategias metodológicas y didácticas diferentes.

El sector determinado por la tecnología y la pedagogía implica la cuestión de cómo enseñar bien con las nuevas herramientas digitales tecnológicas existentes. Mientras que el sector de conocimiento curricular y tecnológico delimita la necesidad de ayudar a los alumnos a aprender con tecnología y sobre cómo seleccionar las herramientas y recursos adecuados para un dado contenido curricular específico.

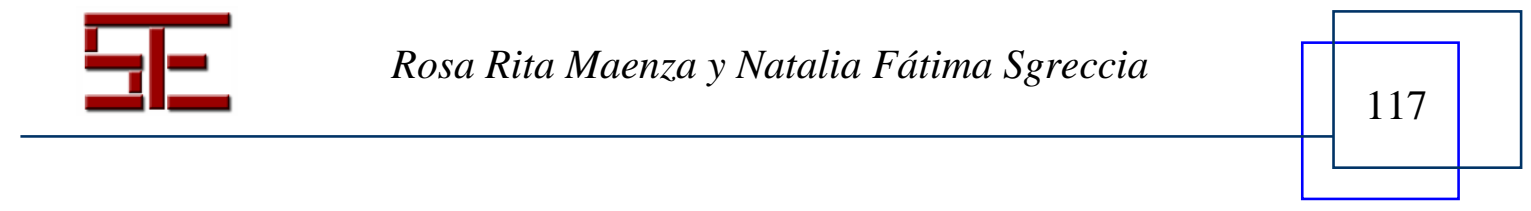




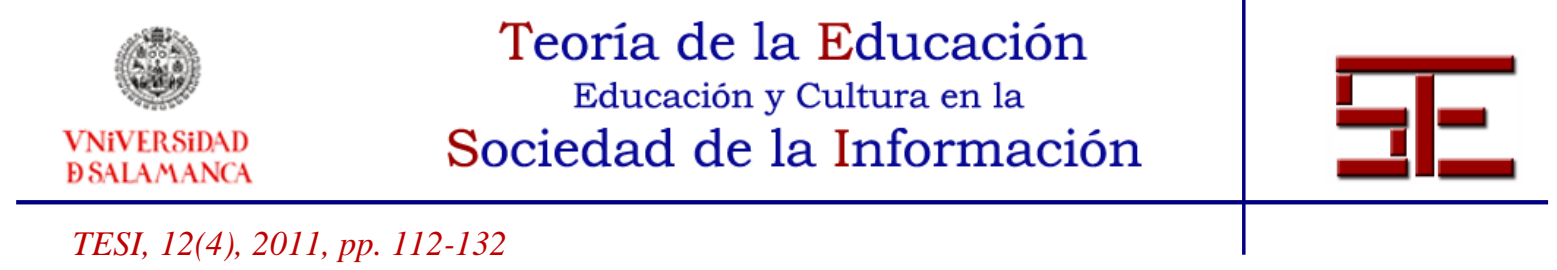

Entonces, en la intersección de todos está el TPACK que claramente vincula los tres tipos de conocimientos y genera la problemática de preparar a los futuros docentes en su ejercicio profesional considerando estos tres aspectos en forma conjunta, procurando la integración de las TIC basadas en el currículum.

Por su parte, Manuel Benito, catedrático de la Universidad del País Vasco, también trata sobre la problemática de la formación del profesorado en un escenario de intensa presencia de TIC ante un cambio del entorno social. Señala que, en este contexto, nuevos roles del profesor deben ser trabajados, entre los que destaca:

- dejar de transmitir información y pasar a asesorar o guiar el aprendizaje, implicando un desplazamiento del foco de la enseñanza al aprendizaje situado en el alumno;

- actuar como facilitador de recursos y adaptador de materiales de diferentes soportes;

- diseñar y producir nuevos entornos de aprendizaje con TIC;

- evaluar los procesos en dichos entornos y contextos;

- propiciar el autoaprendizaje del alumno, garantizando su permanente desarrollo.

Como dice Martínez, hay que formar a un alumno que deberá reunir una serie de capacidades y habilidades nuevas: dominio y capacidad de utilización de los procesos científicos de la ciencia, conocer y utilizar estrategias que le permitan la formación permanente durante toda su vida, tener criterio para la valoración de la información de que disponga o a la que pueda tener acceso, ser capaz de imaginar nuevos caminos o nuevas preguntas que permitan el avance del conocimiento, aceptar posiciones diferentes a las propias y no por ser desconocidas despreciarlas, honesto y éticamente comprometido, capaz de integrarse en grupos de trabajo y por último tratar de conocer y aceptar posturas diferentes a la propia con relación a la concepción de la sociedad y los valores sobre los que se asienta (Martínez, 2007, 45). Estas ideas son aplicables para nuestros alumnos universitarios actuales, futuros docentes.

Frente a esta necesidad, el sistema educativo universitario en Argentina ha comenzado hace unos años una etapa de modificación de planes de estudio, acorde a las nuevas políticas a nivel europeo y latinoamericano tendientes al uso de estándares que posibiliten la acreditación de las carreras y a la definición de los perfiles profesionales a través de competencias.

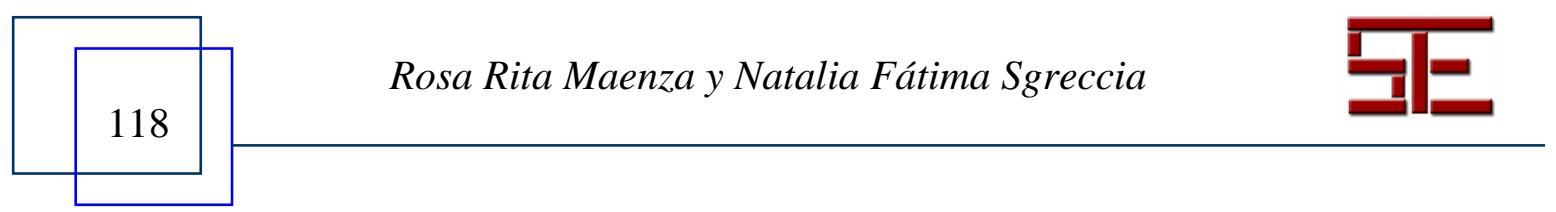




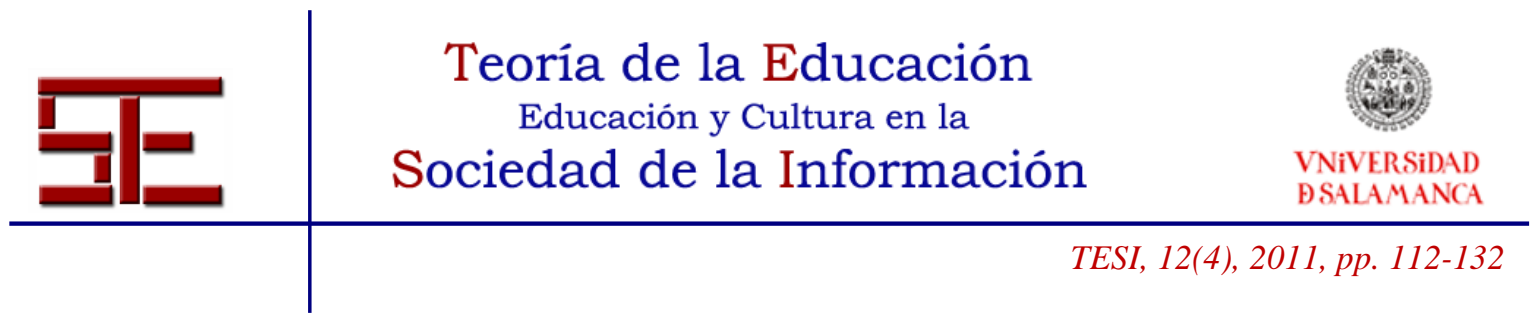

Respecto a la línea trabajo de competencias, en el Proyecto Tunning de América Latina (Beneitone, Esquetini, González, Marty Maletá, Siufi y Wagenaar, 2007) se remarcan los siguientes puntos:

- La obsolescencia rápida de los conocimientos.

- La necesidad de definir competencias que representen una combinación entre el conocer y comprender, saber cómo actuar y cómo ser dentro de la sociedad.

- El corrimiento del centro en el acto pedagógico, los docentes ceden el escenario, el protagonismo, la palabra y el tiempo a los estudiantes.

$\mathrm{Si}$ bien los supuestos de estas transformaciones son evidentes y adquieren una significativa trascendencia en las carreras del Profesorado Universitario, el proceso de implementación en Argentina todavía requiere de mejoras sustantivas.

En particular, en el plan de la carrera Profesorado de Matemática de la Universidad Nacional de Rosario aún no hay una asignatura específica que trabaje la temática de las TIC como recurso educativo. Existen incipientes experiencias llevadas a cabo desde las asignaturas del área Educación Matemática y particularmente desde la asignatura Residencia se han comenzado a introducir algunas prácticas en web 2.0 desde el año 2010.

En este trabajo se muestra una etapa de alfabetización tecnológica llevada a cabo en la asignatura Residencia ubicada en el cuarto y último año de la carrera, siendo una materia donde el residente integra los conocimientos en los campos disciplinar y didáctico con la práctica que realizará en instituciones educativas concretas.

\section{3.- EL APRENDIZAJE COLABORATIVO}

El concepto de aprendizaje colaborativo siempre ha sido objeto de discusión pues existe cierta ambigüedad en el uso del término. Mientras que algunos autores señalan una diferencia entre cooperativo, colaborativo y trabajo en equipo, otros deciden emplear las palabras en forma indistinta.

Entre los trabajos iniciales pueden citarse como extremos a Ovejero (1990), quien declara que un aprendizaje cooperativo es siempre un aprendizaje en grupo, pero que la recíproca no siempre es válida. O como dicen Coll y Colomina $(1990,339)$ "no basta

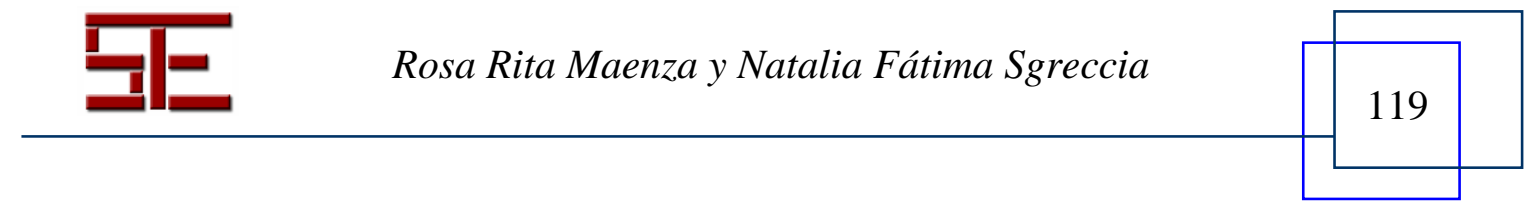




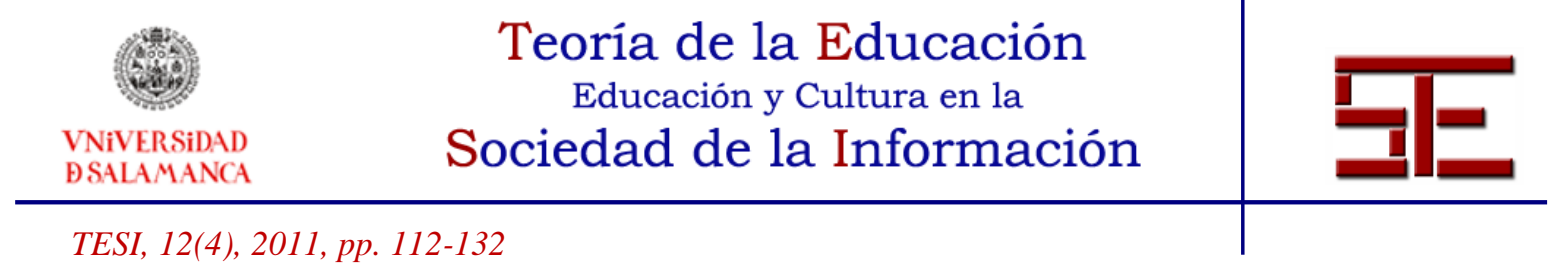

con dejar que los alumnos interactúen o con promover la interacción entre ellos para obtener de forma automática efectos favorables sobre el aprendizaje, el desarrollo y la socialización". Por otro lado, se encuentran las opiniones de Fabra (1994) y Cirigliano y Villaverde (1990), cuyos trabajos están dirigidos al área de dinámicas grupales, y en sus estudios claramente se puede apreciar que las ideas expresadas con respecto a los trabajos en grupo y los aprendizajes que se efectúan en estas situaciones no difieren demasiado con las características descriptas para los aprendizajes cooperativos.

Como trabajo más actual puede citarse a Pere Marquès (2011), quien expone en su ponencia del I Congreso Internacional sobre Metodologías del Aprendizaje Colaborativo a través de las TIC la diferencia entre trabajo en grupo, aprendizaje cooperativo y colaborativo. En un trabajo en grupo muchas veces los estudiantes dividen el trabajo en tareas sencillas y cada uno de ellos hace una parte, esta metodología conocida como división del trabajo o trabajo por relevos no ayuda demasiado a la construcción del conocimiento compartido. En el aprendizaje colaborativo existe un trabajo grupal orientado a la adquisición de aprendizajes, se da autonomía e interdependencia positiva (Johnson y Johnson, 1991). Si el profesor estructura las interacciones entre los alumnos y el reparto de las tareas, lo denomina aprendizaje cooperativo (Dewey, 1938).

Sin entrar en planteos más desarrollados sobre el tema, se considera para este trabajo el concepto de aprendizaje colaborativo como una propuesta educativa en la cual los estudiantes se unen para realizar una determinada tarea (Fernández Berrocal y Melero, 1995) y en donde las interrelaciones entre las personas implican una interdependencia de los unos con los otros, determinando que cada miembro tiene la necesidad de contactar y participar con los demás para perseguir y logran ese objetivo común.

Para MacConnell $(1994,15)$ un "aprendizaje cooperativo implica trabajo conjunto en alguna tarea o cuestión en un modo que promueve aprendizaje individual a través de los procesos de colaboración en el grupo". En este sentido, una tarea cooperativa brinda la oportunidad de aprender a través de la expresión y exploración de diversas ideas y experiencias, usando los diversos recursos disponibles dentro del grupo.

Según este autor, una técnica de trabajo en grupo en la que el trabajo se realiza en paralelo, dividiendo un tema o una actividad entre grupos de personas, los cuales trabajan a la vez en su tema, no puede colocarse como una técnica de aprendizaje cooperativo. La interacción en este caso es mínima comparada a la que puede existir en

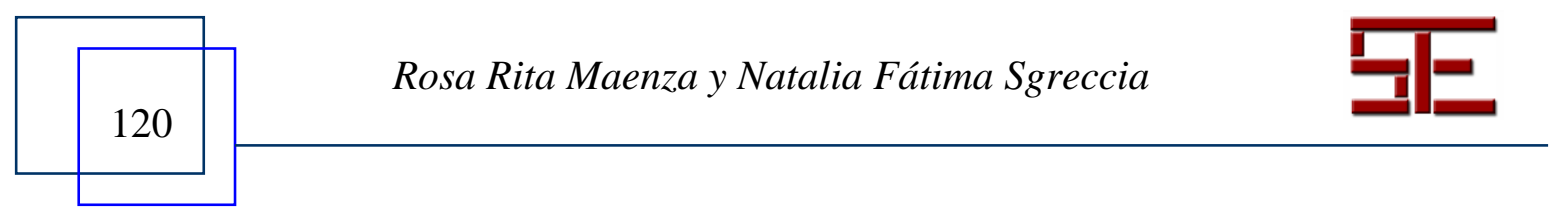




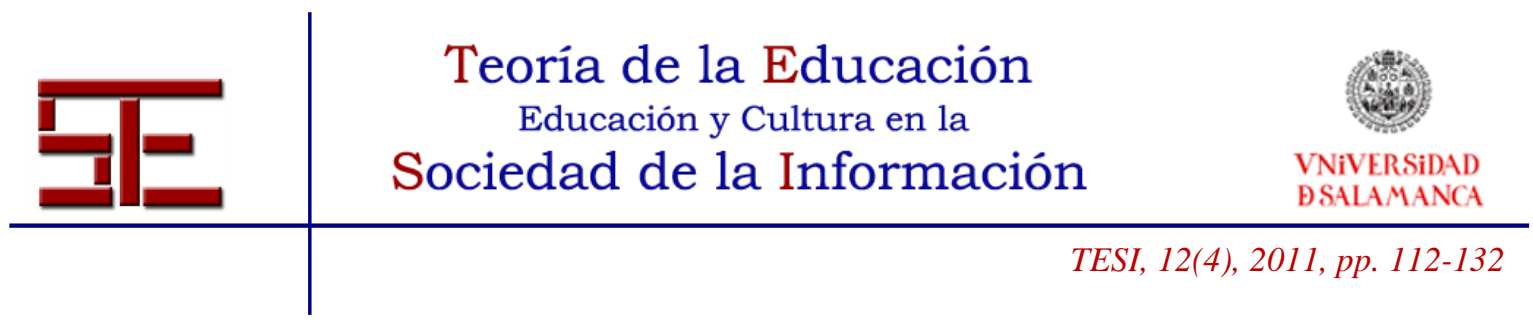

un debate o puesta en común, en donde diferentes opiniones de los participantes abren más posibilidades de diversas posturas.

Mientras no exista un intercambio de ideas, mientras no exista una ayuda mutua entre los integrantes del equipo, mientras las tareas no estén divididas de forma tal que para concluir la meta educativa del grupo se precise que todos lleguen a esa meta, no se puede hablar de un proceso cooperativo que posibilite incremento de socialización ni de aprendizaje cognitivo. Así, los contextos de aprendizaje cooperativo alientan a los estudiantes a pensar acerca de por qué están estudiando y para qué propósitos lo hacen. Esto implica el análisis del pensamiento propio de forma tal de poder compatirlo con los demás miembros del grupo.

\section{4.- PROPUESTA DE LA CÁTEDRA RESIDENCIA}

Bajo el encuadre de los conceptos anteriormente vertidos se presenta la siguiente propuesta de cátedra para la materia Residencia, disciplina que forma parte del Profesorado de Matemática, dictado en la Facultad de Ciencias Exactas, Ingeniería y Agrimensura (FCEIA), dependiente de la Universidad Nacional Rosario en Argentina.

La asignatura se dicta en el cuarto año de la carrera y consiste particularmente en la puesta en práctica de los saberes ya adquiridos durante los años previos de estudio en la carrera universitaria. Está planteada como materia anual con una carga de 300hs durante las cuales se trabaja en la elaboración de cuatro actividades principales.

Uno de los trabajos realizados por los estudiantes se denomina "Práctica de residencia en el nivel superior" y tiene como objetivos: observar y analizar prácticas de docentes reales y situadas; caracterizar los elementos constituyentes de tales prácticas e idear alternativas de trabajo a partir de las situaciones observadas. Específicamente, en esta oportunidad la experiencia de observación fue llevada a cabo en las asignaturas de Matemática de $1^{\circ}$ año de las carreras de grado de FCEIA.

Para efectuar el proceso los alumnos deben ponerse en contacto con los docentes de las respectivas asignaturas y acordar con ellos la posibilidad de realizar las observaciones en sus aulas. También en estos momentos se plantea una situación de negociación en donde se llega a los acuerdos de las posibles actividades que podrían efectuar, pues desde la cátedra se plantea una observación participativa, en la medida de lo posible. La idea es que los residentes tengan la posibilidad de responder a consultas en los

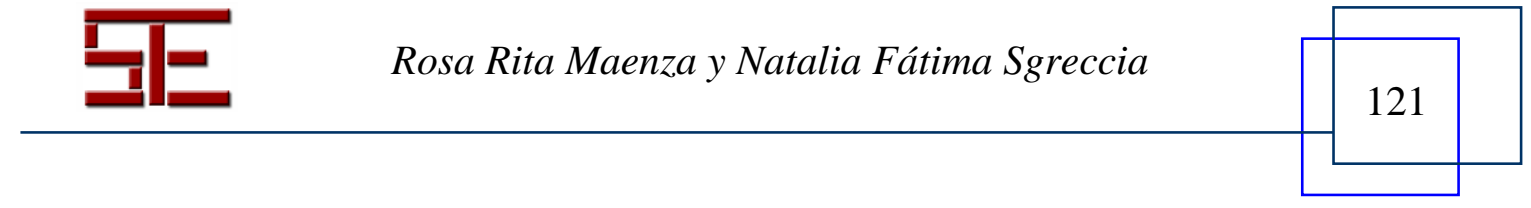






momentos de práctica de la clase, explicar ejercicios y/o demostraciones en el pizarrón, participar de reuniones con los docentes, proponer ejercitaciones extras o bien corregir exámenes, siendo éstos algunos ejemplos de posibles actividades a efectuar.

El informe de todo lo acontecido es efectuado por cada residente, el cual registra la actividad en un formato donde debe existir:

- la presentación del espacio en el que ha realizado la experiencia;

- notas de campo de las observaciones de clases realizadas;

- síntesis de tales observaciones;

- descripción de otras actividades realizadas;

- autoevaluación del propio desempeño;

- reflexiones finales.

Como puede observarse, esta instancia implica la necesidad de conjugar competencias propias de la Matemática y didácticas trabajadas en años anteriores en un producto final que suele resultar agobiante para realizar en forma individual. Si bien existen instancias de trabajo grupal en las sesiones presenciales de la cátedra donde se propicia el debate y la puesta en común para analizar las diferentes situaciones, las mismas hasta ahora parecen no ser suficientes.

Se plantea entonces la necesidad de otro espacio de debate, esta vez, virtual, mediante el cual los residentes puedan explicitar las situaciones reales, describir las experiencias, plantear las problemáticas e inquietudes, expresar sus ideas y comentar sus temores.

La propuesta de implementación consiste en trabajar con el espacio colaborativo ofrecido por Google docs. Cabe aclarar que, si bien existen variedad de herramientas tecnológicas, en principio pareció adecuado emplear este medio por su facilidad de uso y las posibilidades de trabajo en equipo que permite. Por otra parte, según datos estadísticos proporcionados por el sitio de Jane Hart (http://www.c4lpt.co.uk/recommended/top100-2010.html) se trata de una de las herramientas más destacadas para la colaboración educativa en la web.

Básicamente este espacio que actúa como repositorio de documentos y editor de los mismos es una poderosa y amigable herramienta que puede ser empleada por diversos alumnos en diferentes momentos (o en simultáneo) y un mismo objeto puede ser editado en forma cooperativa y colaborativa.

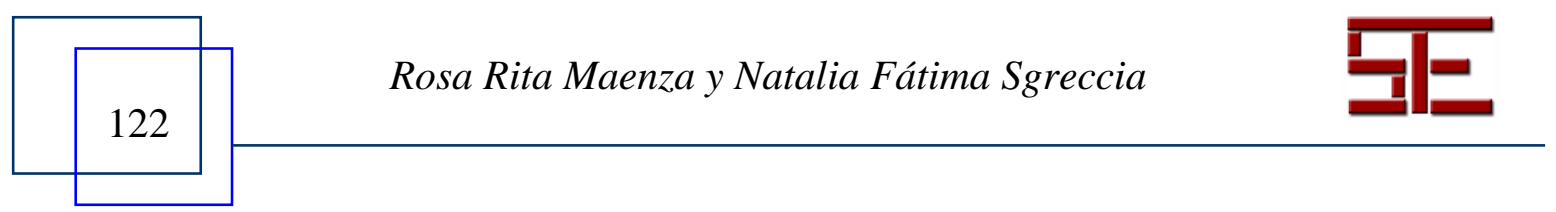




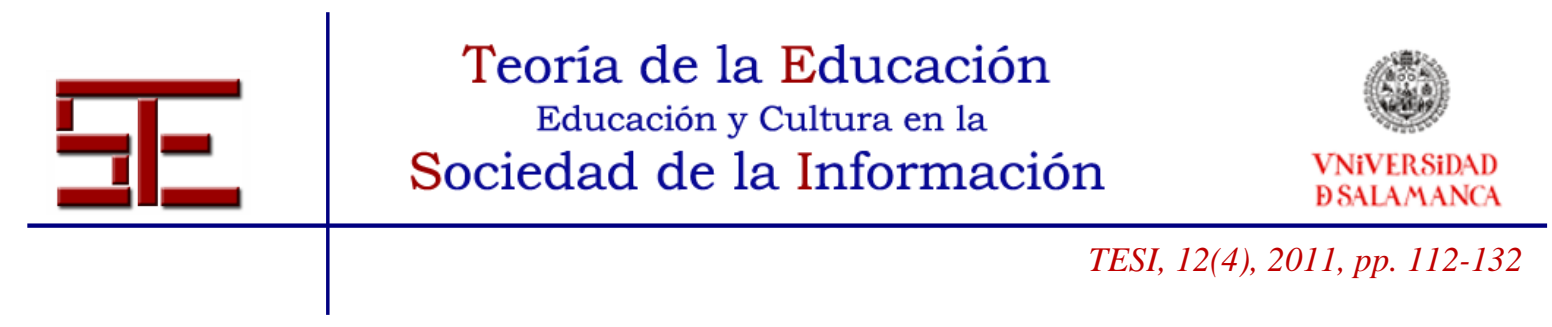

Se introduce esta herramienta web 2.0 con el objetivo principal de generar un espacio de práctica multimedial y de uso compartido, donde, además de ofrecer la posibilidad de alfabetización tecnológica digital, permita gestionar el conocimiento y brinde un ámbito para pedir consejos, recibir ayudas o indicaciones, conocer otras ideas y formas diferentes de encarar una misma realidad.

A continuación se presentan dos relatos extraídos del ambiente ofrecido en Google docs en donde puede observarse el trabajo de los alumnos y las colaboraciones realizadas por sus colegas (empleando otros colores).

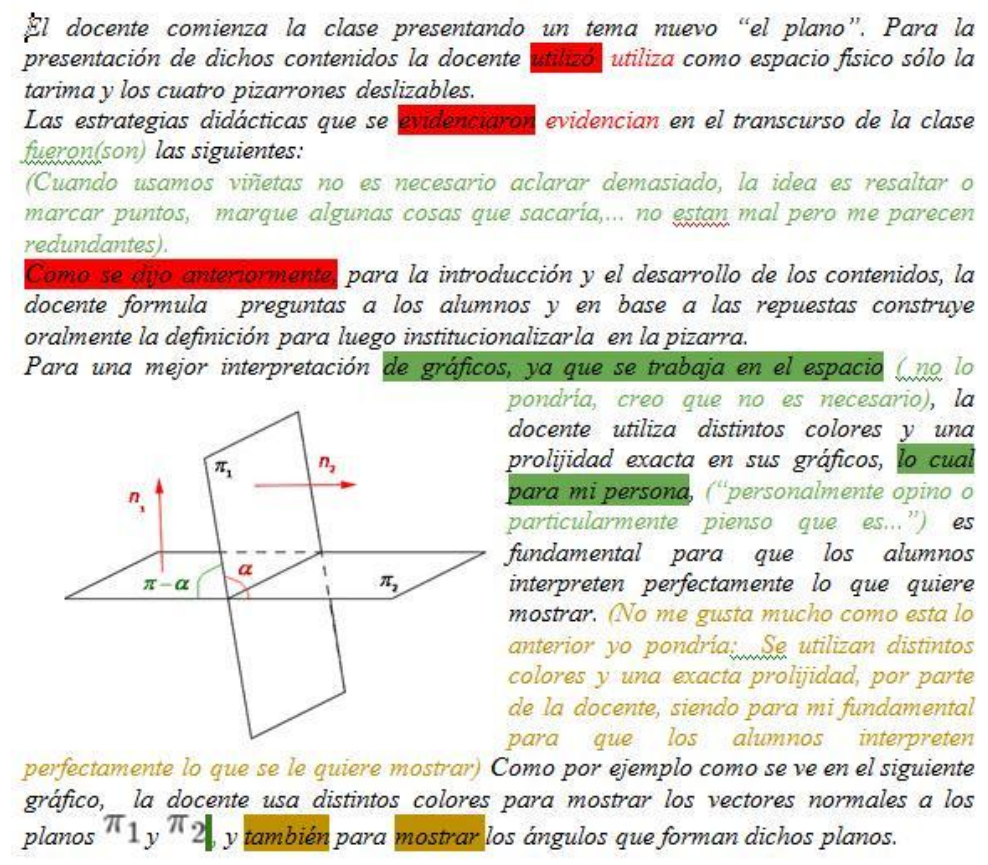

Figura 2 - Relato de residente R1.

Rosa Rita Maenza y Natalia Fátima Sgreccia 


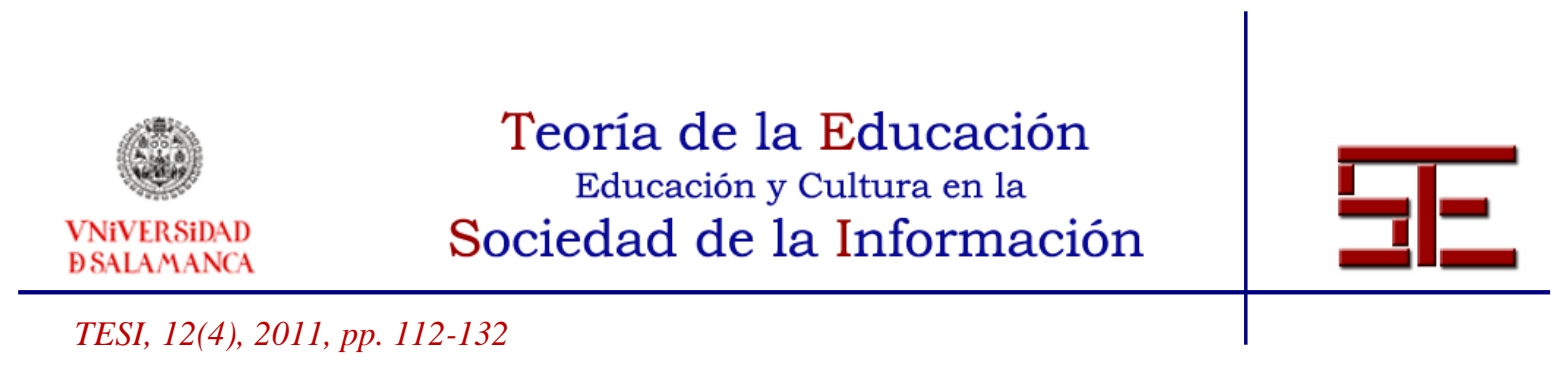

La docente mientras realiza los gráficos en la pizarra les da algunas recomendaciones a los alumnos para que realicen en sus carpetas una mejor gráfica de la situación, como por ejemplo como dibujar una intersección de planos, dejando en líneas de puntos las partes del plano que se encuentran por detrás.

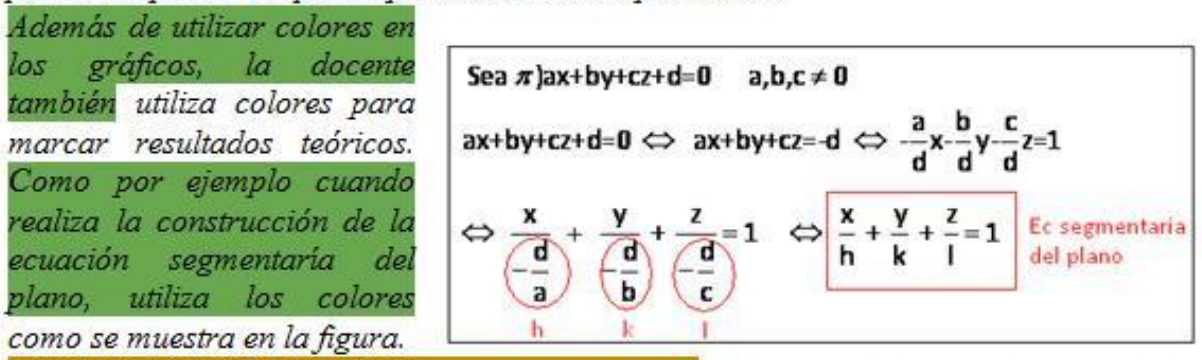

Otra de las estrategias utilizada por la docente es volver a explicar de modo distinto los contenidos escritos en la pizarra. A estas nuevas explicaciones las realiza de forma oral, gráfica o gestual. Con esto (llevará a que) los alumnos tendrán (tengan) más de una explicación y una visión más general del contenido.

Cuando hay conexión entre los contenidos previos y los nuevos, el docente da un breve repaso de aquellos. Como por ejemplo cuando la docente (profesora) expone el tema "la distancia de un punto a un plano" emergió como contenido previo "la proyección de un vector sobre otro", el docente (ella) se toma unos minutos para repasar el tema. El docente no sigue puntualmentae el apunte establecido, ni tampoco usa los mismos ejemplos, lo que hace la docente es que se invenla los ejemplos en el moment $o$, (es inventarlos) esto hos lleg me llevó a preguntarle porque el motivo, y su respuesta fue para que tengan mas variedad de ejemplos, lo que me hace pensar que es una estrategia.

Figura 3 - Relato de residente $\mathbf{R} 2$.

\section{1.- Metodología de trabajo}

La metodología de trabajo colaborativo empleada consistió en dividir al grupo aula (17 alumnos) en tres equipos de tres alumnos y dos equipos de cuatro. La división fue propuesta por las docentes de la cátedra, considerando la afinidad del contenido trabajados por los practicantes.

Dentro de cada equipo uno de los integrantes era el encargado de crear el espacio en Google que luego debía ser compartido con todos los otros estudiantes. En particular, los responsables directos del trabajo colaborativo eran los integrantes del mismo grupo, el resto podía ayudar si quería hacerlo.






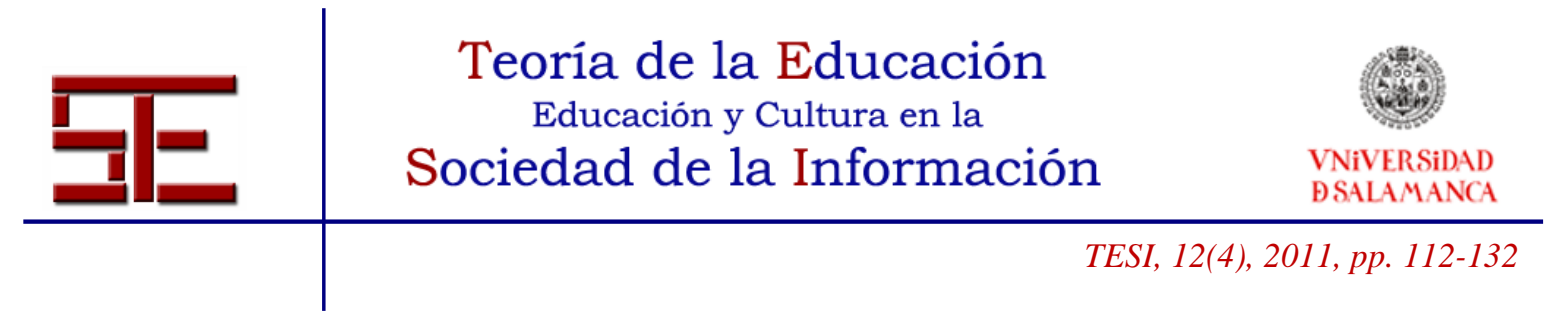

Las intervenciones en los documentos de sus compañeros de grupo debían ser efectuadas en diferentes colores: rojo (integrante 1), verde (integrante 2), marrón (integrante 3) y lila (integrante 4, si hubiera).

Para poder efectuar la actividad colaborativa se plantean en forma definida las pautas que deben ser tenidas en cuenta durante las nueve semanas determinadas para el desarrollo de la práctica mencionada. A continuación se muestran en formato de tabla las indicaciones dadas para cada una de las semanas.

\begin{tabular}{|c|c|c|c|c|c|c|c|c|c|}
\hline \multirow{2}{*}{ Actividad } & \multicolumn{9}{|c|}{ Semana } \\
\hline & $18 / 04$ & $25 / 04$ & $02 / 05$ & 09/05 & $16 / 05$ & $23 / 05$ & $30 / 05$ & $06 / 06$ & $13 / 06$ \\
\hline $\begin{array}{l}\text { Crear una cuenta de gmail } \\
\text { y una carpeta en Google } \\
\text { Docs para compartir con el } \\
\text { grupo de Residencia }\end{array}$ & $X$ & & & & & & & & \\
\hline $\begin{array}{l}\text { Relatar las observaciones } \\
\text { de clases y otras eventuales } \\
\text { actividades desarrolladas }\end{array}$ & X & & $X$ & & $X$ & & & & \\
\hline $\begin{array}{l}\text { Corregir los documentos } \\
\text { de sus compañeros } \\
\text { realizando aportes en } \\
\text { diferentes colores }\end{array}$ & & $X$ & & $X$ & & $X$ & & $X$ & \\
\hline $\begin{array}{l}\text { Atender a las correcciones } \\
\text { efectuadas }\end{array}$ & & $X$ & & X & & & $X$ & X & \\
\hline $\begin{array}{l}\text { Ir completando la } \\
\text { introducción del trabajo }\end{array}$ & & $\mathrm{X}$ & & & & & & & \\
\hline $\begin{array}{l}\text { Ir avanzando en la síntesis } \\
\text { de los relatos }\end{array}$ & & & & $X$ & & & & & \\
\hline $\begin{array}{l}\text { Redondear la síntesis de } \\
\text { los relatos }\end{array}$ & & & & & & X & & & \\
\hline $\begin{array}{l}\text { Realizar una } \\
\text { autoevaluación }\end{array}$ & & & & & & $X$ & & & \\
\hline $\begin{array}{l}\text { Avanzar hacia las } \\
\text { conclusiones }\end{array}$ & & & & & & & X & & \\
\hline $\begin{array}{l}\text { Revisar todo lo producido } \\
\text { hasta el momento }\end{array}$ & & & & & & & & $X$ & \\
\hline $\begin{array}{l}\text { Cerrar el informe y } \\
\text { preparar la defensa oral del } \\
\text { trabajo }\end{array}$ & & & & & & & & & $X$ \\
\hline
\end{tabular}

Tabla 1 - Pautas semanales para el desarrollo de la actividad.

Rosa Rita Maenza y Natalia Fátima Sgreccia 


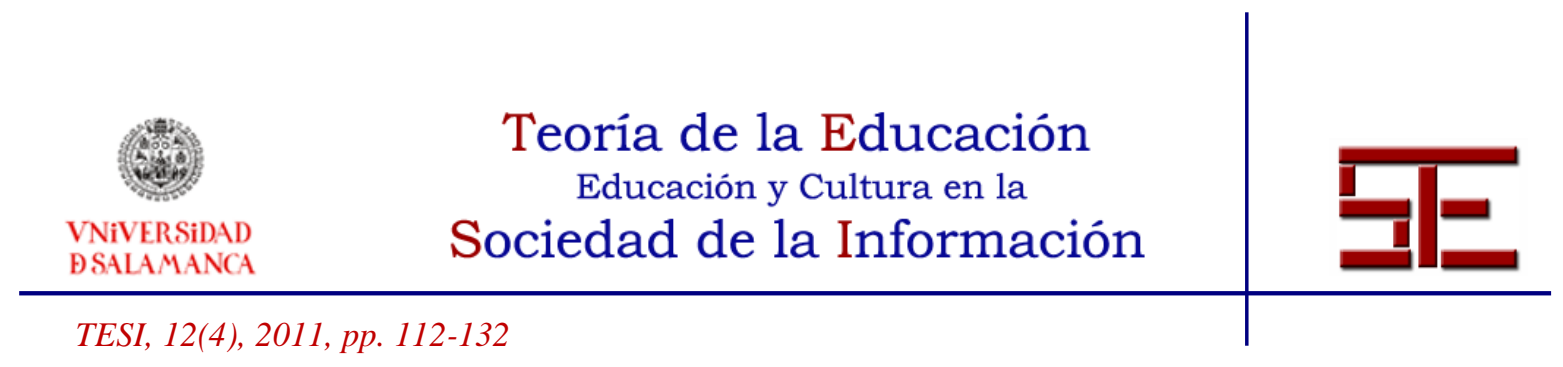

\section{5.- RESULTADOS OBSERVADOS}

Como primer resultado, creemos que este tipo de experiencia formativa constituyó una guía para el aprendizaje colaborativo de los futuros profesores en Matemática, pues se detectaron distintos tipos de "soportes" (ver tabla) en el sentido de andamios que posibilitaron la construcción de sus vivencias como residentes en el nivel superior.

Esos soportes pueden ser categorizados en tres tipos particulares, donde en cada uno de ellos se evidencian componentes específicos.

\begin{tabular}{|l|l|}
\hline \multicolumn{1}{|c|}{ Soportes } & \multicolumn{1}{c|}{ Componentes } \\
\hline Didáctico-matemático & $\begin{array}{l}\text { Desempeño del docente observado } \\
\text { Desempeño de los estudiantes observados } \\
\text { Relaciones pedagógicas }\end{array}$ \\
\hline Técnico-tecnológico & $\begin{array}{l}\text { Ortografía y redacción } \\
\text { Inserción de símbolos y gráficos } \\
\text { Organización del informe }\end{array}$ \\
\hline Afectivo-emocional & $\begin{array}{l}\text { Tránsito por su experiencia de práctica docente } \\
\text { Retroalimentación en la elaboración del informe } \\
\text { Reconocimiento de logros }\end{array}$ \\
\hline
\end{tabular}

Tabla 2 - Soportes destacados y sus componentes en el trabajo colaborativo.

En lo que respecta al desempeño docente los alumnos se enfocaron en las elecciones del profesor en relación al uso de ciertos recursos; en los formatos de introducción de los temas a trabajar; en las problemáticas de las instancias de un examen (antes, durante y después); en las explicitaciones de cierto malestar docente y en las reacciones explícitas o no de sentirse observado por otros mientras se está trabajando en la clase.

Dentro del desempeño de los estudiantes observados, los residentes remarcaron el trabajo grupal que se les proponía; el compromiso demandado en la superación de los aprendizajes y el interés manifestado en acciones concretas tendientes a proporcionar un buen clima de trabajo en el aula, remarcando el respeto y considerando situaciones especiales que se producen en los espacios.

Por otro lado, como relaciones pedagógicas se destacan el vínculo docente alumno y el contrato didáctico existente y las relaciones de poder entre los docentes de la misma cátedra, con los señalamientos sobre cómo las mismas son importantes y también influyen en la gestión eficiente del grupo aula.

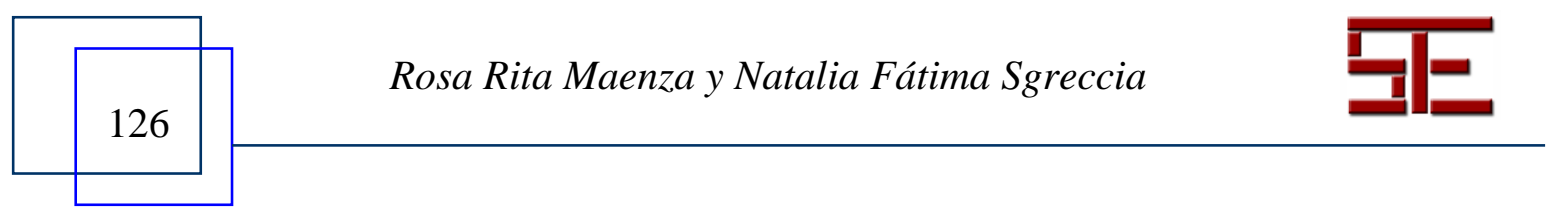




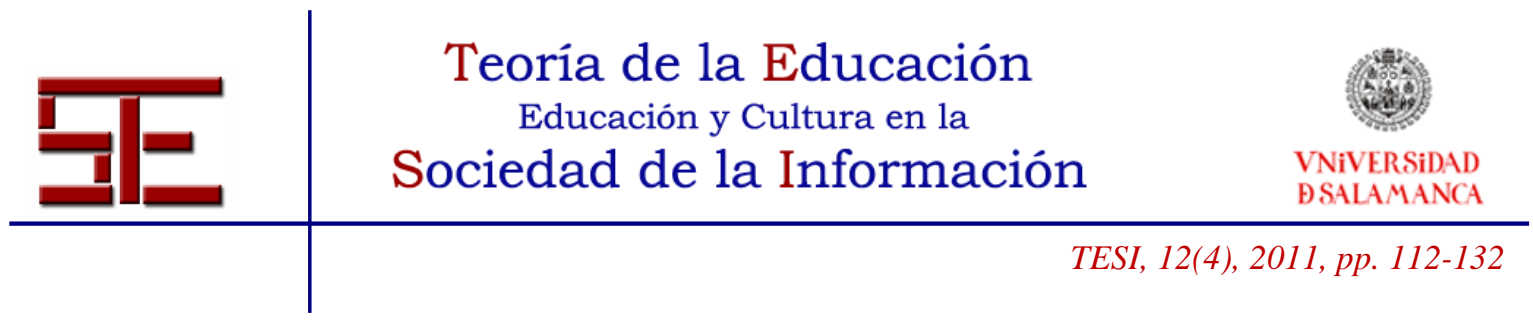

Como ítem soporte técnico-tecnológico, se pueden resaltar las apreciaciones realizadas a los compañeros en cuanto a las correcciones de ortografía y redacción referida al uso de: mismos tiempos verbales, el empleo de palabras más apropiadas para describir ciertas situaciones y la organización del informe.

También dentro de este soporte se observan indicaciones procedimentales que se dan los alumnos a sus compañeros referidas a la inserción de símbolos y gráficos o al uso del editor de ecuaciones para la introducción de fórmulas matemáticas.

Finalmente, en el soporte afectivo-emocional, se destacan reflexiones realizadas por los residentes respecto al tránsito de su experiencia; sobre la retroalimentación en el proceso de elaboración del informe y el reconocimiento de logros y avances efectuados.

\section{6.- COMENTARIOS FINALES}

En nuestra facultad, la asignatura Residencia ha sido caracterizada por años una materia donde se consideraba la actuación individual del estudiante y existía un trabajo personal importante. Esto llevaba a que ciertos rasgos de la personalidad propios de cada uno de los residentes terminaban haciendo diferencias notables en los resultados de las prácticas. Es decir, la forma de trabajo en la disciplina formativa llevaba a que ciertas capacidades y habilidades innatas de los alumnos prevalecieran más allá de las indicaciones y los comentarios realizados en la cátedra.

Este rasgo característico de los individuos viene hace tiempo siendo estudiado por las empresas, en donde se detectaron ciertas personas que con los años llegan a adquirir experiencias importantes las que se pierden debido a la desvinculación laboral. En los ámbitos empresariales esta situación es trabajada desde la disciplina gestión de conocimiento que busca promover el desarrollo del capital intelectual y el capital social.

En el ámbito empresario se define el concepto de gestión de conocimiento como el conjunto de procesos y sistemas que permiten que el capital intelectual de una institución aumente de forma significativa, mediante la gestión de sus capacidades de resolución de problemas de forma eficiente (Careaga Butter y Avendaño Veloso, 2006).

En una clase cualquiera, podemos definir el concepto de gestión de conocimiento llevado a cabo dentro del grupo, tratando de crear una cultura organizativa que estimule

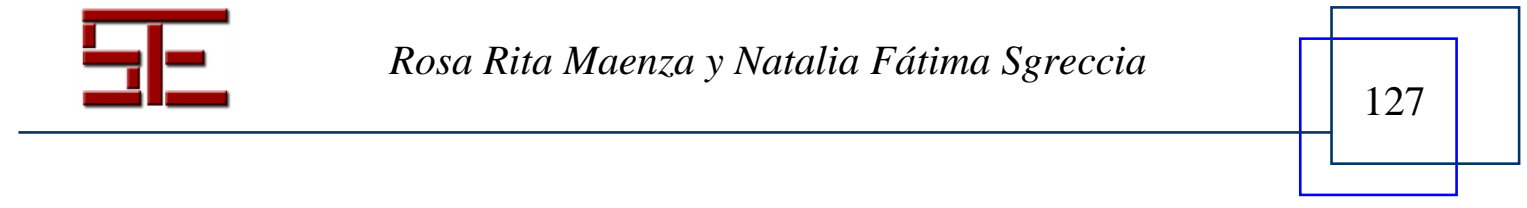




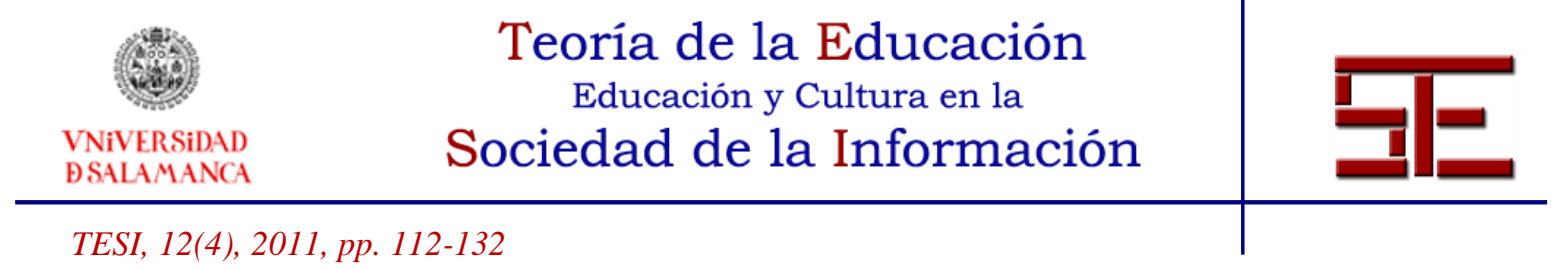

y promueva acciones tendientes a compartir conocimiento mediado tecnológicamente, por ejemplo, empleando un espacio virtual como el dado por Google docs.

Entendiendo por conocimiento no solo el personal (producto de la relación individual existente entre el sujeto que experimenta la acción y el intento que éste realiza para reformular conceptualmente la experiencia), sino el grupal (que requiere una responsabilidad personal de compartir y hacer explícito el conocimiento a los otros miembros del grupo).

Así puede hablarse de un conocimiento social, constituido por el repertorio de experiencias culturales de docentes que ya ejercen, junto con ideas e ideales de futuros docentes. La teoría de redes señala que los lazos que conforman las redes añaden valor a los individuos y los grupos, mantener las relaciones con otros hace que las personas aprovechen mejor las oportunidades, accedan a más recursos y compartan relatos de vida. De esta forma, el grupo aprende en la medida que las personas que lo conforman son capaces de formarse generando vínculos entre ellos.

Sin duda, los mayores escenarios de desarrollo de capacidades de resolución de problemas de un docente se llevan a cabo durante su práctica profesional, cuando se enfrenta en el aula a innumerables variables, factores, condiciones y situaciones que deben ser salvadas. En esos momentos se ponen en juego, además del capital intelectual, el capital humano (valores, actitudes, aptitudes y capacidades).

Por tal motivo se considera el momento de cursado de Residencia como el período idóneo para plantear esta iniciativa innovadora de prácticas pedagógicas empleando diferentes herramientas de intercambio e interacción existentes en Internet.

Pero creemos además que la innovación en TIC en una institución, carrera o clase no necesariamente es sinónimo a uso de la última tecnología; más bien se consolida por un cambio cualitativo, que altera las condiciones y características de trabajo y de las prácticas tal como eran realizadas anteriormente (Montero y Gewerc, 2010).

En particular, la experiencia planteada permitió y demandó de los residentes el desarrollo de ciertas capacidades en el dominio de las TIC, el trabajo colaborativo y la adaptación a nuevas situaciones, las cuales se conjugaron en forma práctica y vivencial en el empleo del entorno digital.






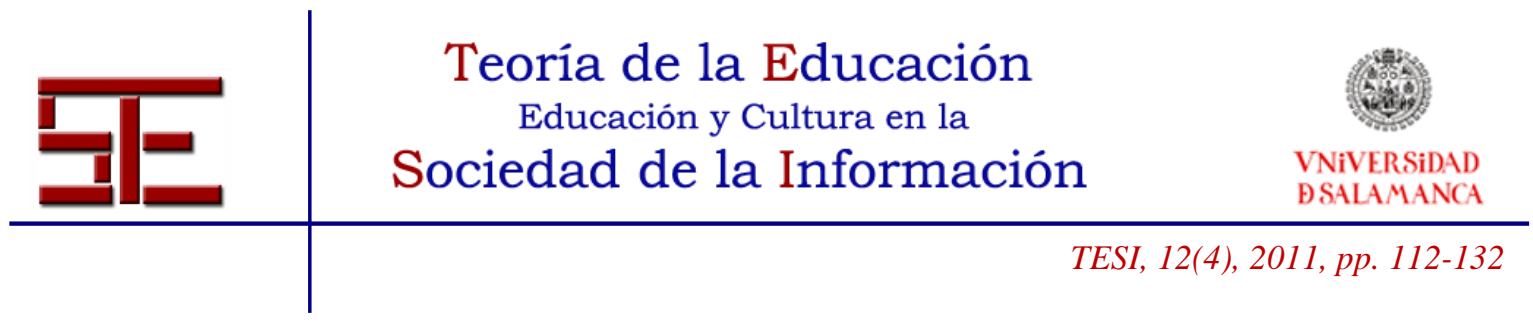

Consideramos que los tres tipos de "soportes" identificados se constituyen en elementos-clave del aprendizaje colaborativo que fue construyendo este grupo de residentes y se transfieren a aspectos que necesitan como profesional de la Educación Matemática: conocimiento matemático y su didáctica, habilidades técnico-tecnológicas e inteligencia emocional.

A lo largo de todo el proceso pudo apreciarse una genuina constitución de una CVP. El compartir los trabajos permitió que los residentes pudieran relacionarse, generando vínculos positivos. Sus intervenciones procuraban posiciones de consenso y evidenciaban atención y sensibilidad en las variadas situaciones. También se rescata el aprecio de las ideas provenientes de los compañeros residentes, la apertura a la escucha, la aceptación de consejos o sugerencias y una fuerte motivación por ayudar al otro a enriquecer su labor.

En este sentido quedó claro que el objetivo fundamental del trabajo colaborativo era enriquecer todos y cada uno de los trabajos, mejorando su calidad. En todo momento las apreciaciones vertidas en los diferentes relatos fueron consideradas como propuestas superadoras para la elaboración de los mismos.

Constatamos, desde los testimonios, la trascendencia del trabajo en una CVP concreta, mediada por herramientas de la web 2.0, como una forma para desarrollar las competencias en TIC y la inteligencia colectiva en Educación Matemática.

Ante una realidad de transformación, cambio y flexibilidad permanente, los sistemas educativos deben adaptarse y ofrecer respuestas a las nuevas demandas existentes. En particular, como formadoras de formadores, consideramos que tenemos la responsabilidad de que los futuros docentes accedan al uso de las TIC en Educación Matemática, que puedan conocer y reflexionar al respecto.

\section{BIBLIOGRAFÍA}

Arnal, D. (2007). Conceptos de web 2.0 y biblioteca 2.0: origen, definiciones y retos para las bibliotecas actuales [Versión electrónica]. El profesional de la información, 16 (2), 95-106.

Beneitone, P.; Esquetini, C.; González, J.; Marty Maletá, M.; Siufi, G.; Wagenaar, R. (2007). Reflexiones y perspectivas de la Educación Superior en América Latina.

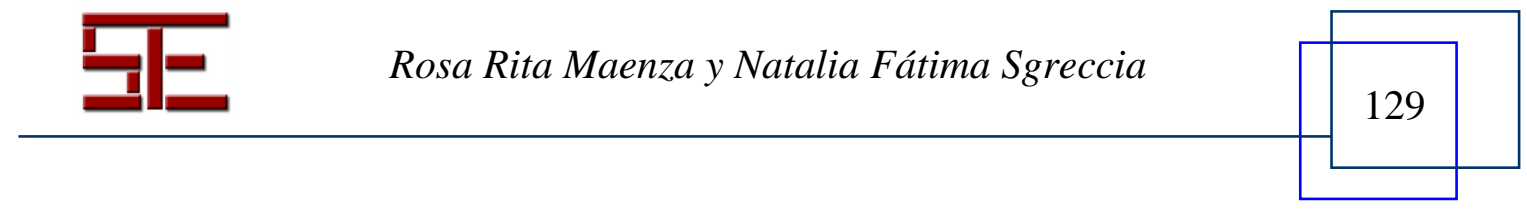




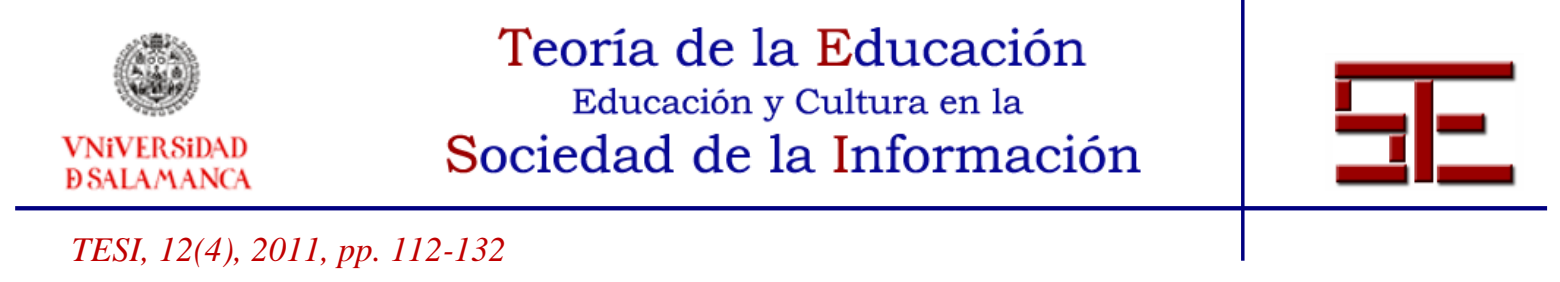

Informe final. (Proyecto Tuning. América Latina 2004-2007). Universidad de Deusto. Extraído el 23 febrero, 2011, de http://tuning.unideusto.org/tuningal.

Benito, M. (2011). La formación del profesorado: formación inicial, desarrollo profesional y modelos. Ponencia presentada en el VI Encuentro Internacional EducaRed 2011. Actitud 2.0: aprender es compartir, Madrid, España.

Carr, N. (2011). Superficiales ¿Qué está haciendo Internet con nuestras mentes? Madrid: Taurus.

Cirigliano, G. y Villaverde, A. (1990). Dinámica de grupos y educación. Buenos Aires: Humanitas.

Coll, C. y Colomina, R. (1990). Interacción entre alumnos y Aprendizaje escolar. En Coll, C., Palacios, J. y Marchesi, A. (Eds.), Desarrollo psicológico y educación, vol. II, Psicología de la Educación (pp. 335-352). Madrid: Alianza.

Copertari, S. \& Trottini, A. (2011, febrero). Pedagogía de la virtualidad y gestión del conocimiento. El caso del campus Virtual UNR y el repositorio Hipermedial dinámico. Ponencia presentada en el XIV InforEdu: Congreso Internacional de Informática Educativa, La Habana, Cuba.

De la Torre, A. (2006). Web educativa 2.0. Edutec. Revista Electrónica de Tecnología Educativa, 20. Extraído el 11 Junio, 2011, de http://www.uib.es/depart/gte/gte/edutece/revelec20/anibal20.htm.

Dewey, J. (1938). Experience and education. Indianapoles: Kappa Delta Pi.

Fabra, M. (1994). Técnicas de grupo para la cooperación. Barcelona: CEAC.

Fernández Berrocal, P. y Melero Zabal, M. (1995). Interacción social en contextos educativos. Madrid: Siglo XXI.

Harris, J. (2011). Integración de las TIC basada en el Currículum. Ponencia presentada en el VI Encuentro Internacional EducaRed 2011. Actitud 2.0: aprender es compartir, Madrid, España.

Johnson, D. \& Johnson, F. (1991). Joining together: Group theory and groups skills. Nueva Jersey: Englewood Cliffs, Prentice-Hall.

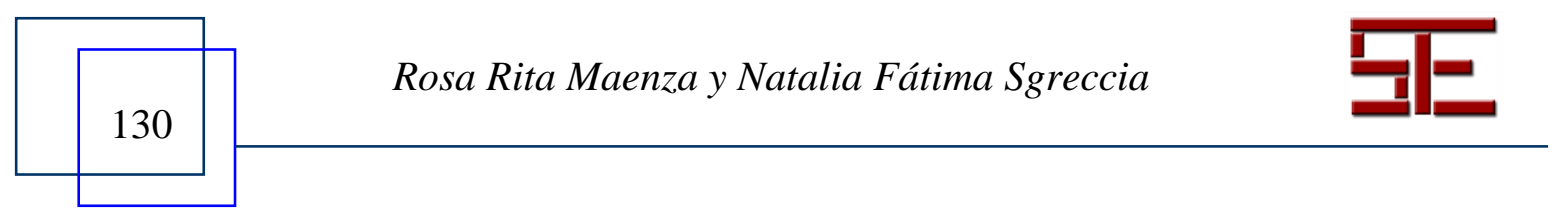




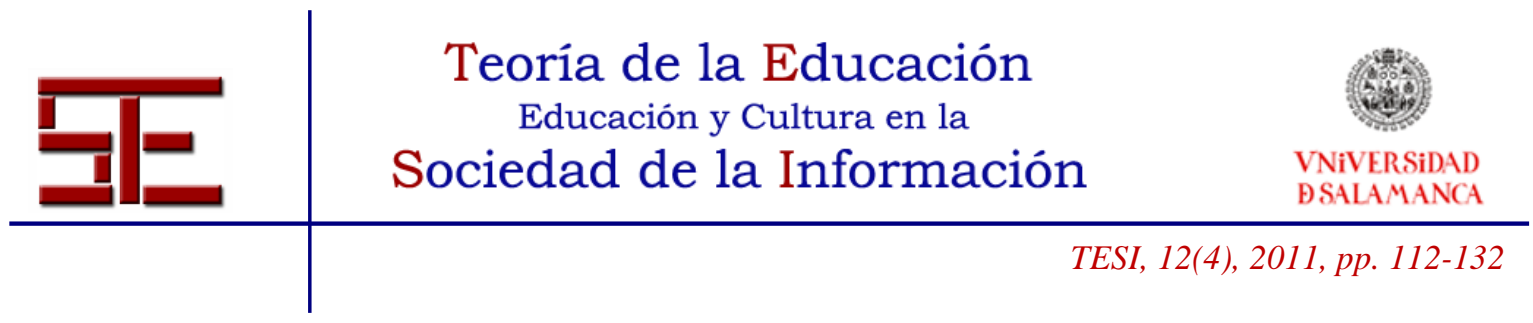

Lévy, P. (2007). Cibercultura. Barcelona: Anthropos.

MacConnell, D. (1994). Implementing computer supported cooperative learning. London: Kogan Page.

Marquès, P. (2011, junio). Modelos didácticos de aprendizaje colaborativo con TIC. Ponencia presentada en el I Congreso Internacional sobre Metodologías del Aprendizaje Colaborativo a través de las TIC. Salamanca, España.

Martínez, F. (2007). Los problemas culturales en el uso educativo de las nuevas tecnologías: La formación de profesores y alumnos para esta nueva situación. [Versión electrónica]. Revista de Tecnología de Información y Comunicación en Educación, 1 (2), 25-64.

Montero, M. \& GEWERC, A. (2010). De la innovación deseada a la innovación posible. Escuelas alteradas por las TIC [Versión electrónica]. Profesorado. Revista de Currículum y Formación del Profesorado, 14 (1), 303-318.

O'Reilly, T. (2005). Web 2.0: Compact Definition? O'Reilly Home. Extraído el 20 de Junio, 2011 de http://radar.oreilly.com/archives/2005/10/web-20-compactdefinition.html.

Organización de Estados Iberoamericanos para la Educación, la Ciencia y la Cultura (OEI) (2009, abril). El proceso de elaboración de las Metas Educativas 2021. La educación que queremos para la generación de los bicentenarios [Versión electrónica]. XII Conferencia Iberoamericana de Ministros de Cultura, Lisboa, Portugal.

Ovejero, A. (1990). El aprendizaje cooperativo: Una alternativa eficaz a la enseñanza tradicional. Barcelona: Promociones y Publicaciones Universitarias.

Siemens, G. (2006). Knowing Knowledge [Versión electrónica]. Creative Commons.

Wenger, E. (2001). Comunidades de práctica. Barcelona: Paidós.

Wenger, E.; McDermott, R.; Snyder, W. (2002). Cultivating communities of practice. Boston: Harvard Business School Press.

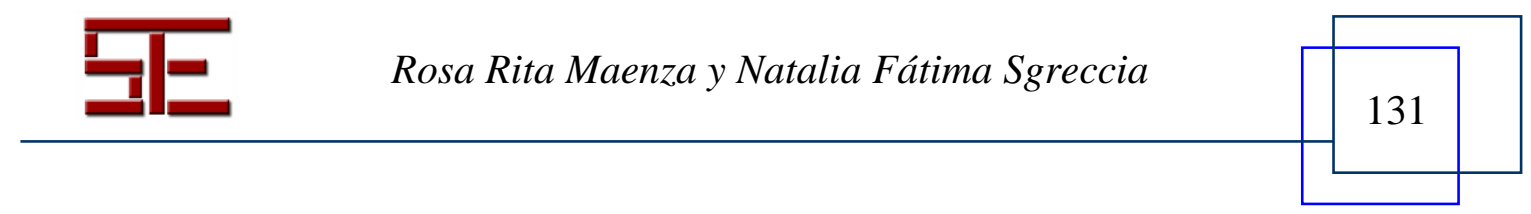




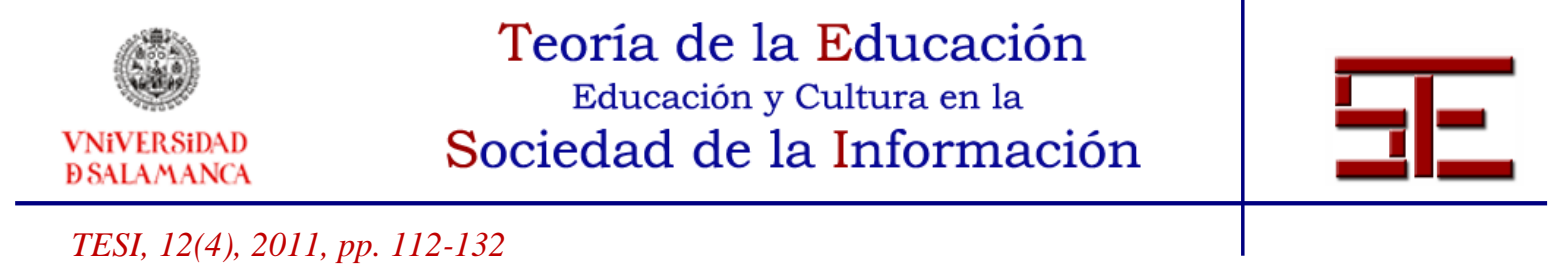

Para citar el presente artículo puede utilizar la siguiente referencia:

Rita Maenza, R. y Fátima Sgreccia, N. (2011). Aprendizaje colaborativo mediatizado como estrategia para el desarrollo de competencias: una experiencia con residentes del profesorado de matemática. Revista Teoría de la Educación: Educación y Cultura en la Sociedad de la Información. 12(4), 112-131 [Fecha de consulta: dd/mm/aaaa].

http://campus.usal.es/ revistas_trabajo/index.php/revistatesi/article/view/8529/8615 